\title{
CONSIDERATIONS ON THE PARENT MATERIAL IN THE SOIL DEVELOPED ON THE EVAPORITE DEPOSITS FROM STANA (CLUJ DISTRICT)
}

\begin{abstract}
HOREA BEDELEAN ${ }^{1}$
ABSTRACT. This research concerned three profiles developed on Eocene (Priabonian) gypsum parent material from Stana (Cluj district) in order to investigate their properties. The soil and parent material samples were collected from individual horizons in each profile. Both the mineralogical and structural-textural features of the parent material (evaporitic deposits) reflect the depositional context. From a mineralogical point of view, the deposits are represented by gypsum, and anhydrite. Typical sulfate facies are present: laminitic, nodular, gypscretic, and entherolitic. Physical and mineralogical properties of the soil layers were determined in the laboratory. The field observations and the results of the analyses allowed us to classify the soil as a rendzinic regosol, according to the Romanian System of Soil Taxonomy (S.R.T.S. 2000).
\end{abstract}

Key words: Stana, gypsum, soil

\section{INTRODUCTION}

The soil, as a surface component of the earth crust, is a natural, dynamic and independent body composed of mineral particles and containing organic matter. It has a specific morphological organization due to particular pedogenetic processes produced and ruled by different elements and factors.

The main pedogenetic factors are represented by lithology (parent rock), climate (thermo-pluviometric regime), landscape (altitude, exposure, slope), direct influence of the organisms (plants and animals, man included) and by time (considering the long periods necessary for completing the pedogenetic process).

One of the main pedogenetic factors is represented by parent rock, that significantly contributes in defining the soil type. Soil properties such as thickness, grain distribution (texture), chemical composition, physical-mechanical, and hydrophysical features are directly determined by the parent rock. Several types of soil may develop starting from the same parent material; in the same time, various types of soil may form in similar conditions on different parent rocks.

The parent rock is also used as a diagnostic criterion when defining some of the soil types: rendzina, vertisols, alluvial sols, etc..

The paper concerns the study of some properties of soils developed on evaporite deposits (mainly represented by gypsum) from Stana area (Cluj district).

The mineralogy of the studied soils suggests a relationship between the parent material and the soils developped. The nature of mineral components in the soil influences the composition of the soil solution and the status of the soluble matter in the soil, thus restricting its natural fertility level.

\footnotetext{
1 "Babeş-Bolyai” University, Department of Geology, Str. Kogălniceanu 1, 3400 Cluj-Napoca, Romania.
} 


\section{HOREA BEDELEAN}

The petrography of the parent rock determines the mineral and chemical composition of the soluble matter in the soil, as well as their accumulation and circulation path, which define the pedological processes and soil fertility.

The contribution of parent rock and parent matter to the soil formation and structure is represented by the specific supply of chemical elements resulting from the alteration of primary minerals.

\section{MATERIALS AND METHODS}

The studied area is located in the north-western part of Transylvania Depression between Cluj-Napoca and Huedin.

A moderate continental climate characterizes the region. The mean annual temperatures vary between +2 and $+6^{\circ} \mathrm{C}$ in Gilau area and between +7 and $+9^{\circ} \mathrm{C}$ in the whole Transylvanian Depression. The average annual relative humidity is $75-80 \%$.

From a geological point of view, the deposits outcropping in the area are represented by Priabonian sedimentary rocks: Valea Nadăşului Formation (continental unit, consisting of red clays, sandstones, microconglomerates, sands), and Jebuc Formation (evaporitic deposits, mainly represented by gypsum with dolomicrites, oolitic limestone, marly limestone with Anomia). On their top the Cluj Limestone Formation (shallow marine platform limestones with marly, lumaschell-type interlayers) outcrops.

Three profiles and various outcrops of soils developed on gypsum as parent material were studied and sampled. They are located along the Stana valley (across the Stana railway station). Based on detalied field survey and measurements on the samples, the main properties of the soil were determined.

The outcrops were investigated macroscopically, and the samples were studied microscopically and by X-ray diffraction.

The description of the soil profiles was realized by using several standard properities such as: colour, structure, texture, soil reaction $(\mathrm{pH})$. These properties were determined in soil samples taken from each profile, according to Miclăuş\&Blaga (1982).

The texture analysis was performed according to the hydrometer method.

The XRD analyses (X-ray diffraction) on parental material and soil samples were performed using a DRON-3 tool with a $\mathrm{Cu}$ anticathode.

The soil reaction $(\mathrm{pH})$ was measured on soil suspension $(<2 \mathrm{~mm})$ in distiled water (1:2.5) by using a portable $\mathrm{pH}$-meter of a $\mathrm{pH}$-330-type, having an electrode combined with an integrated temperature sensor SenTix 41.

\section{RESULTS}

Within the studied area, Jebuc Formation is represented by an evaporitic series consisting of a succession of evaporite sequences (individual layers and composed units, 0.5-2 m thick), with centimetre thick clay interlayers.

A vertical variation of the facies that was noticed in the outcrops marks the transition from the lagoon facies in the base to coastal sabkha in the upper part.

The laminitic facies (fig. 1) consists of a succession of gypsum laminae interlayered with clayey laminae. The variations indicate successive changes of the basin dynamics, depending on the duration of the basin stability stages. The seasonal changes of temperature and water chemistry are reflected by the colour change 60 
recorded by the laminae. The clayey interlayers are products of the deposition of suspended materials, as a result of stable evaporite regime with periodic supply of material.

The nodular facies (fig. 2) is represented by white-greyish nodules with variable sizes $(1-10 \mathrm{~cm})$, embedded in a greyish-greenish clayey matrix. The sulfate that has precipitated is mainly anhydrite but also subordinately gypsum, as it is typical for sabkha environments.

"Sabkha" environments refer to supralittoral areas that are periodically flooded by sea water. They are located in regions with warm and dry climate, thus with scarce precipitations and intense evaporation, the general aspect being that of desert beaches. The sediments to be found in sabkha environments were formed in tidal and supratidal areas and mainly consist of sulfates (gypsum, anhydrite).

These associations were formed as a result of early diagenesis, when the intense evaporation leads to the increase of salt concentration in the interstitial solutions. As a result of the reduced precipitations regime, the salts supply is mainly represented by sea water, which periodically immerses the area. When the critical saturation concentration of the respective solutions is reached, the salts precipitate; this process is located in the proximal area of the lagoon, being influenced by a rich supply of siliciclastic material. As a result, nodules may form in poorly consolidated clayey or carbonate sediments, by interstitial precipitation or by carbonate substitution (Anastasiu, 1988).

The nodules form by the addition of new crystals to the existing mass and not by overgrowth on already existing crystals (Shearman, 1986). This growth pattern leads to the removal of the clay material in-between the nodules, until they get into direct contact. Their joining takes place along planes marked by thin clayey films. The nodular texture that results in this process is known as "chicken - wire". The growth of anhydrite nodules leads to the formation strata with horizontal extension.

In the presence of continental fresh water, the anhydrite nodules undergo rehydration giving birth to secondary gypsum, especially in the landwards sector of the sabkha environment.

The enterolithic facies - this structural type is a result of the curving of the evaporite layers. It is common in secondary gypsum beds formed close to the surface by hydration of anhydrite rocks (Shearman, 1986), with an increase of the volume of $63 \%$. By similitude with structures from modern sediments, as well as by comparison of secondary gypsum with anhydrite rocks (Shearman, 1986) concludes that this structure type is the result of primary growth processes.

Diagenetic processes - due to the lithostatic pressure, secondary gypsum forms after deposition and burial, especially in relationship to the presence of phreatic fresh water. The crystals are fibrous and they form aggregates (millimeter to centimeter thick) oriented more or less parallel to the stratification. The fibers are perpendicular to the vein walls or to the laminite stratification.

From a mineralogic point of view, based on microscopy and XRD results, the studied evaporite deposits consist of gypsum CaSO ${ }_{4} \cdot 2 \mathrm{H}_{2} \mathrm{O}$, anhydrite $\left(\mathrm{CaSO}_{4}\right)(>90 \%)$ and very scarce celestite. Besides, in subordinate amounts, calcite, dolomite, smectite, illite, kaolinite, silica varieties (amorphous and cryptocrystalline) are present. The carbonates represent impurities (also in the soil profile), or rarely individualized layers or larger aggregates. Sometimes they are intimately associated with clay minerals. 
The clay interlayers (fig. 3 ) - The clay fraction has an allochtonous origin, being the result of periodic terrigenous supply; its composition reflects the types of rocks from the source area.

The XRD results indicated a composition dominated by montmorillonite (60-65\% of total rock mass), and illite (10\%); associated are sulfates (diagenetic fibrous gypsum) and quartz and feldspar clasts.

The presence of montmorillonite is related to the alteration of volcanic rocks (banatites) from the neighbouring Gilău and Vlădeasa mountains.

Its genesis took place by alteration and solification processes in a humid and alkaline environment (cold and humid climate). The resulting material was afterwards transported as terrigenous supply towards supratidal and littoral environments. By periodical supply, the material has accumulated either as clayey individual layers - as an effect of a humid, pluviatile regime with terrigenous supply in a brackish environment, or mixed within the anhidrite-gypsum deposits.

Illite is subordinated, being related to the alteration of phyllosilicates (mainly from crystalline rocks) under alkaline conditions; the source rocks outcrop are relatively remote to the studied area.

Another possible source of clay material is represented by the mica-rich clays within the Valea Nadăşului Beds.

The soils were classified according to the existing maps and the criteria proposed by Romanian Soil Taxonomy (SRTS-2000) and FAO/ UNESCO based on morphological and psycho-chemical characteristics.

According to the Romanian Soil Taxonomy (SRTS-2000), the soil developped on evaporite deposits in Stana area can be characterized as belonging to the Class PROTISOL (immature-divided, or immature soils based on the SRCS-1980 standards), Type: REGOSOL (RS), Subtype: RENDZINIC REGOSOL (RS-Rz).

Based on the FAO/UNESCO (1990) nomenclature, the studied soil can be considered as a gypsiric regosol (Rgy); in the Romanian terminology, "gypsiric" refers to soils containing $>5 \%$ gypsum in the depth of $20-50 \mathrm{~cm}$ from the surface (Andreiaşi, Mihalache,1999).

The soil profile is short in length and poorly developed (about $80-90 \mathrm{~cm}$ ), the parent rock located very close to the soil surface, consisting of Ao-C-Rrz horizons (fig. 4). The Ao horizon is poorly represented, it has a light colour and a low content of organic material $(<1.5 \%)$; it is followed by $\mathrm{C}$ horizon consisting of poorly consolidated parent material resulted from infiltration of water and sulfate dissolution.

The morphological properties of the soil under study are presented in Table 1. The soil texture is influenced by the relatively high amount of gypsum (Table 2). The amount of sulfates is variable along the profile, an increasing trend with depth being recorded. A relatively high amount of gypsum was determined along the profile; besides untransformed clayey clasts from the clayey interlayers of the parent rock, with a similar mineralogical composition (mainly smectite) are present.

The profiles are rich in carbonates, the carbonates probably originating from the upper stratigraphic horizons (Cluj Limestone), as a result of subsequent levigation and precipitation. 
Table 1

The morphological properties of the soil from Stana

\begin{tabular}{|c|c|c|}
\hline Horizon & Depth $(\mathrm{cm})$ & Main features \\
\hline Ao & $10-15 \mathrm{~cm}$ & $\begin{array}{l}\text { Colour: light brown-grey } \\
\text { Texture: medium } \\
\text { Structure: poorly developped, subangular or } \\
\text { granulate polyhedral } \\
\text { Skeleton: } 5-25 \% \text { poorly skeletal, with gypsum } \\
\text { fragments } \\
\text { Organic material: rarely plant roots, other organic } \\
\text { material } \\
\text { Wavy gradual boundary } \\
\mathrm{pH}=7.62 \text { (low alkaline) }\end{array}$ \\
\hline C & $15-60 \mathrm{~cm}$ & $\begin{array}{l}\text { Horizon consisting of partially disintegrated and } \\
\text { decomposed parent material, relatively not } \\
\text { affected by soil formation processes; } \\
\text { Colour: grey } \\
\text { Texture: medium (in the first half) } \\
\text { Structure: absent } \\
\text { Skeleton: absent; mud clasts may be present } \\
\text { Cement: carbonate } \\
\text { Poorly developped soil formation processes } \\
\text { Wavy gradual boundary } \\
\mathrm{pH}=7.65-7.72 \text { (low alkaline) }\end{array}$ \\
\hline $\mathrm{Rrz}$ & $60-120 \mathrm{~cm}$ & $\begin{array}{l}\text { Partly transformed parent rock. } \\
\text { Colour: light grey } \\
\text { Clayey clasts and gypsum fragments (from the } \\
\text { parent rock) are present } \\
\mathrm{pH}=7.67 \text { (low alkaline) }\end{array}$ \\
\hline \multicolumn{3}{|c|}{$\begin{array}{l}\text { Low humus content }(<1.5 \%) \text {, decreasing with depth } \\
\text { Weak alkaline reaction } \mathrm{pH}>7\end{array}$} \\
\hline
\end{tabular}

Table 2

Soil texture

\begin{tabular}{|c|c|c|c|c|c|c|}
\hline \multirow[b]{2}{*}{ Horizon } & \multirow{2}{*}{$\begin{array}{l}\text { Depth } \\
\text { (cm) }\end{array}$} & \multicolumn{3}{|c|}{ Grain size distribution (\%) } & \multirow[b]{2}{*}{ Texture } & \multirow{2}{*}{$\begin{array}{c}\text { Texture } \\
\text { Class }\end{array}$} \\
\hline & & $\begin{array}{c}\text { Sand } \\
2-0.02 \mathrm{~mm}\end{array}$ & $\begin{array}{c}\text { Silt } \\
0,02-0.002 \mathrm{~mm}\end{array}$ & $\begin{array}{c}\text { Clay } \\
<0.002 \mathrm{~mm}\end{array}$ & & \\
\hline Ao & $0-15$ & 38.0 & 42.3 & 19.6 & medium & Loam \\
\hline $\mathrm{C}$ & $15-40$ & 44.0 & 39.1 & 16.9 & medium & Loam \\
\hline $\mathrm{C}$ & $40-60$ & \multicolumn{5}{|c|}{ GYP SUM } \\
\hline Rrz & $60-120$ & \multicolumn{5}{|c|}{ GYPSUM } \\
\hline
\end{tabular}




\section{HOREA BEDELEAN}

\section{CONCLUSIONS}

The faciesal and mineralogical studies of the outcrops of the evaporite formation from Stana showed a transition from lagoon facies (alternating laminae of gypsum with clay) to coastal sabkha (stromatolitic and nodular gypsum). The mineralogical composition was originally anhydritic and subordinately gypsiferous. By hydration gypsum formed, according to the following path: anhydrite nodules, laminated to enterolithic structures.

The soil formed on evaporite deposits is characterized by a short profile consisting of the Ao, C and Rrz horizons. It may be assigned to regosol, but lacking the typical features, being developped on an evaporite parent rock.

The studied soil profiles from Stana are rich in gypsum. Besides gypsum and anhydrite, also clay minerals (mainly smectite, and subordinately illite) are present. Organic material was identified, in small amounts.

\section{REFERENCES}

Anastasiu N., 1988, Petrologie sedimentară, Ed.Tehnică, 366p., Bucureşti Andreiaşi N., Mihalache N., 1999, Solurile României, Ed. Ex Ponto, 229p., Constanța Miclăuş V., Blaga Gh., 198), Lucrări practice la Pedologie, Tipo „Agronomia”, 124p., Cluj-Napoca Shearman D.J., ,1986, Les facies evaporitiques de Sabkha-Depots evaporitiques. Edit. Technip. Paris. 


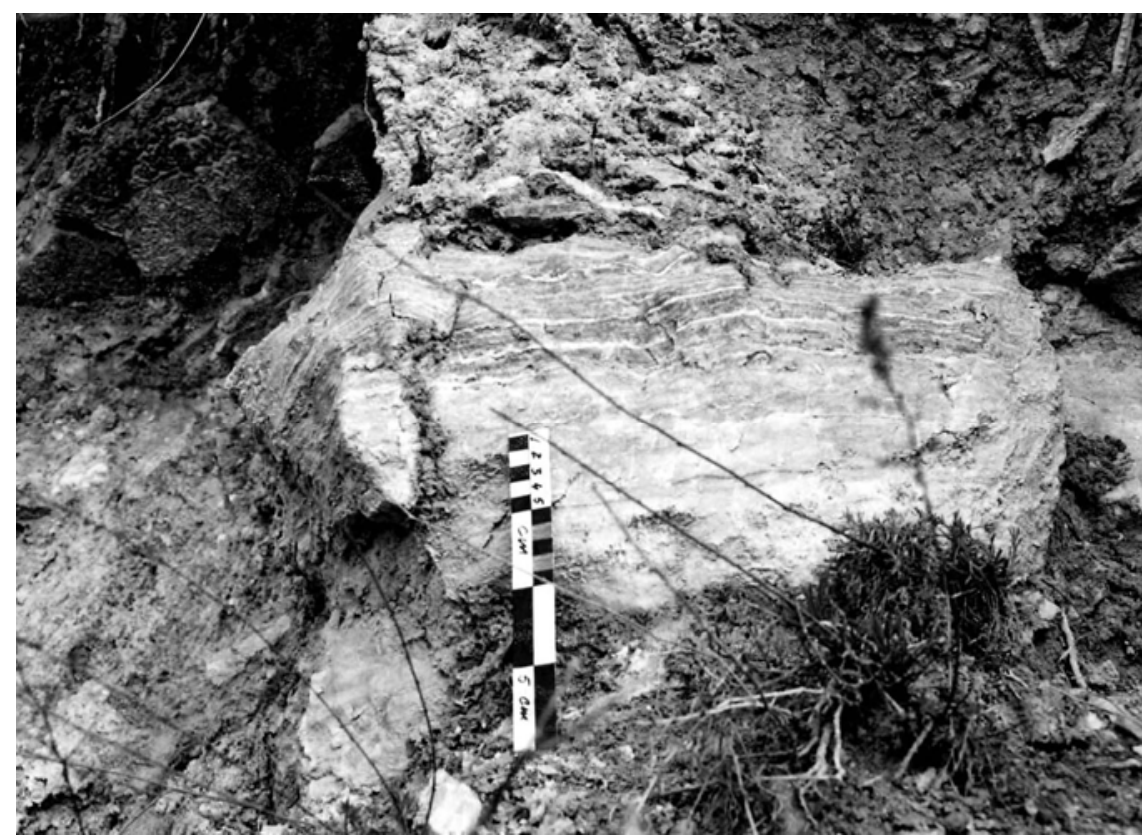

Fig. 1 - Laminitic facies in evaporitic series (Jebuc Formation) - Stana (Cluj county). It consists of a succession of gypsum laminae interlayered with clayey laminae.

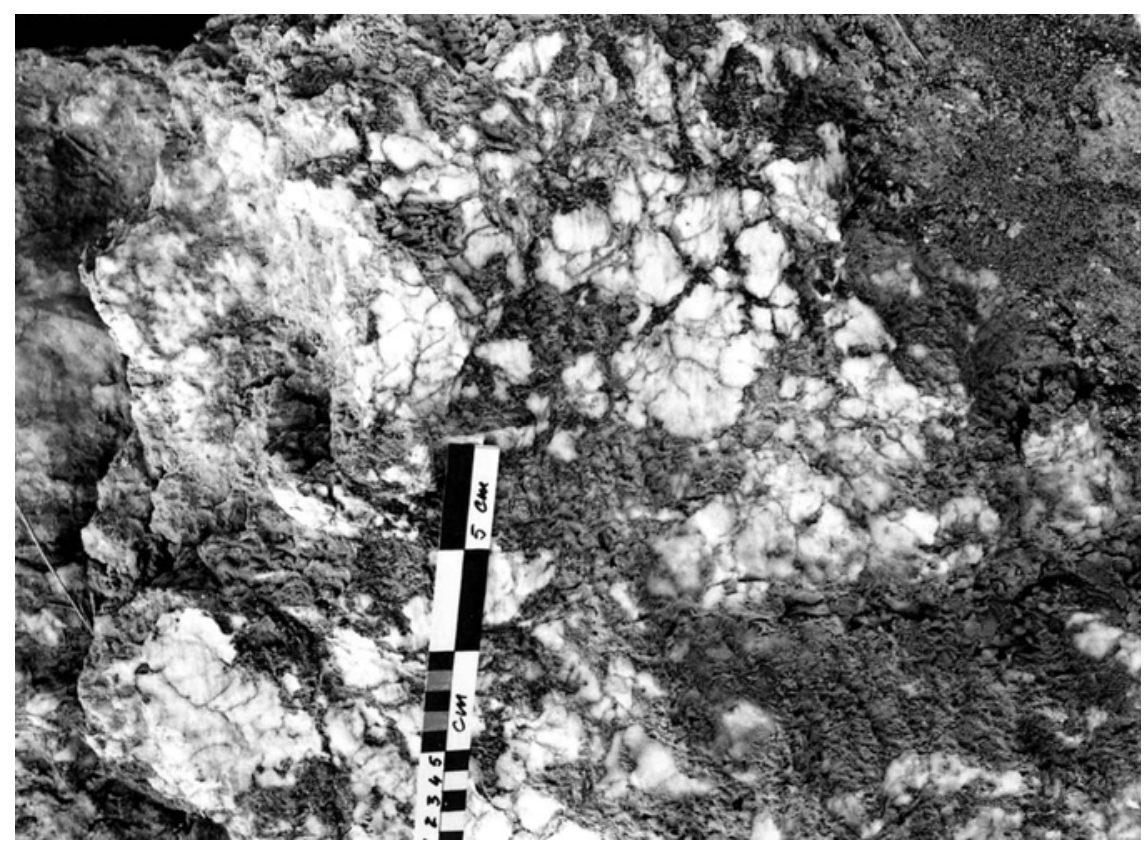

Fig. 2 - Nodular facies in evaporitic series (Jebuc Formation) - Stana (Cluj county). Nodules of gypsum embedded in a greyish-greenish clayey matrix. 


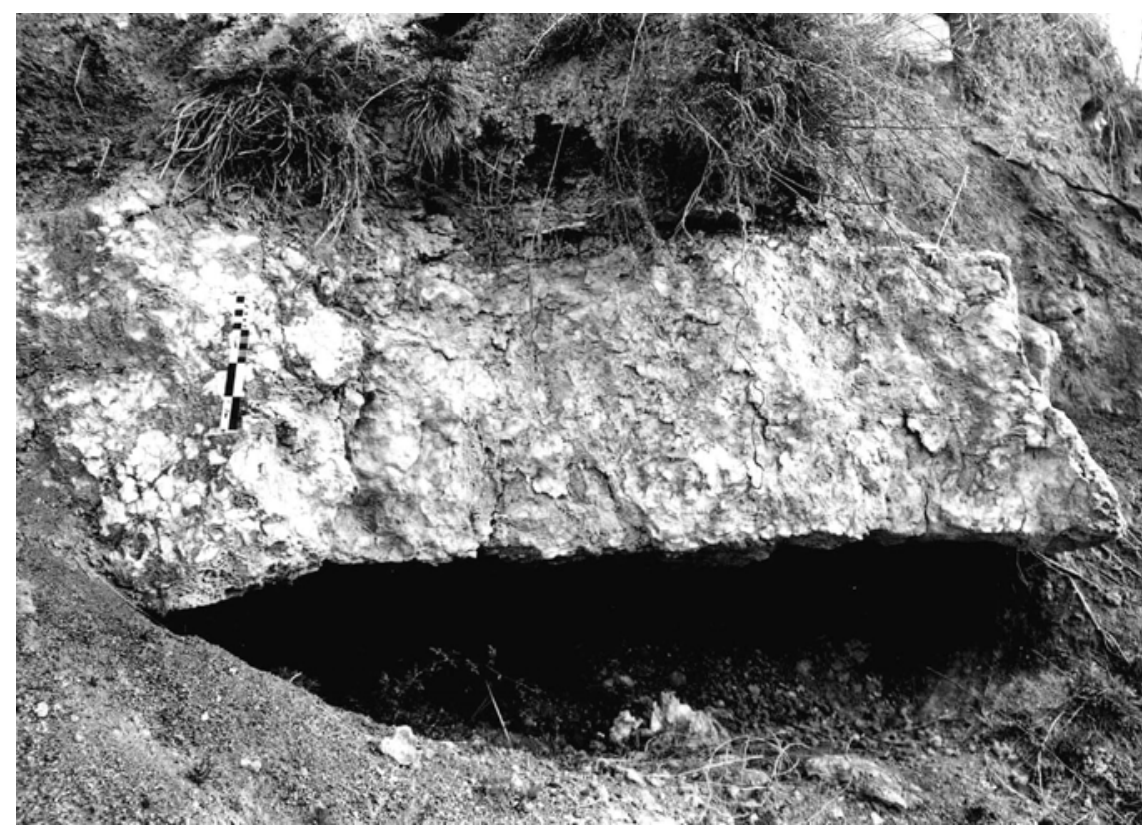

Fig. 3 - The clay interlayers in evaporitic series (Jebuc Formation) - Stana (Cluj county).
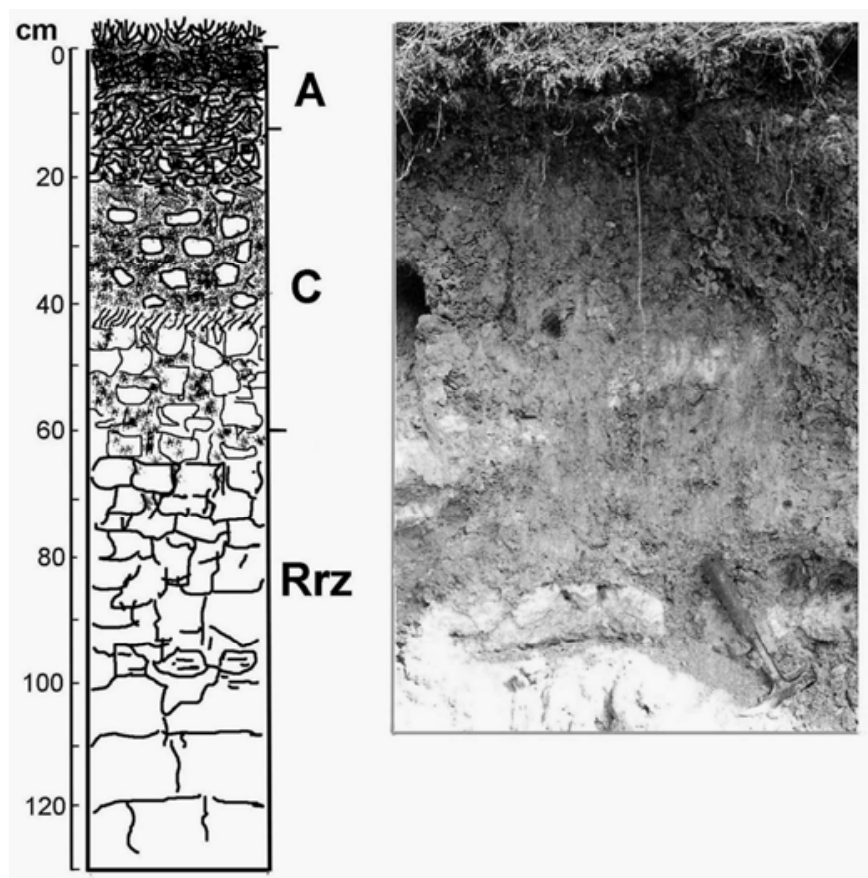

Fig.4 - The soil profile formed on evaporite deposits - Stana (Cluj county). 